\title{
Syntheses of Poly(ethylene oxide) Macromonomers Carrying Tertiary Amine and Quaternary Ammonium End Groups
}

\author{
Takamichi Senyo, Yuji AtAgo, Huanan Liang, Renhua Shen, and Koichi Ito ${ }^{\dagger}$ \\ Department of Materials Science, Toyohashi University of Technology, Tempaku-cho, Toyohashi 441-8580, Japan
}

(Received January 23, 2003; Accepted March 30, 2003)

\begin{abstract}
Vinylbenzyl alcohol, partially alkoxidated with potassium naphthalene, was used successfully to initiate living polymerization of ethylene oxide to afford $\alpha$ - $p$-vinylbenzyl- $\omega$-hydroxy poly(ethylene oxide) (PEO) macromonomers. The $\omega$-hydroxy end-groups were quantitatively transformed to tertiary amines either by tosylation followed by reaction with potassium 2-dimethylaminoethoxide or by Williamson synthesis with 2-dimethylaminoethyl chloride in the presence of sodium hydride. $\omega$-Quaternary ammonium-ended PEO macromonomers were also quantitatively obtained by reaction with iodomethane.
\end{abstract}

KEY WORDS Poly(ethylene oxide) / Macromonomers / p-Vinylbenzyl End-Group / Tertiary Amine End-Group / Quaternary Ammonium End-Group / End-Group Transformation / Heterotelechelics /

Poly(ethylene oxide) (PEO) is one of wellknown, water-soluble, nonionic polymers, and its macromonomers have also been a subject of considerable interest because of their unique amphiphilic properties as well as their many potential applications in various fields, including coatings, cosmetics, ion-conductors, polymeric catalysts, and reagents, and biomedicals. ${ }^{1}$ As usual, styryl or methacryloyl functions have been introduced as a (co)polymerizable end group, say $\alpha$-end group, of the macromonomer, while the other $\omega$-end group is also feasible to introduce another functionality. So far to our knowledge, hydroxyl, ${ }^{2,3}$ carboxylate, ${ }^{4-6}$ sulfonate, ${ }^{7,8}$ aldehyde,, 90 and perfluoroalkyl ${ }^{11}$ groups have been reported. In most cases $^{3-11}$ some elaborate procedures have been involved either in anionic polymerization of ethylene oxide (EO) or in end-group transformation, while 2hydroxyethyl methacrylate was used together with a Lewis acid to initiate cationic EO polymerization to give poly(ethylene glycol) monomethacrylate in one step. $^{2}$

Our recent strategy in PEO macromonomer synthesis includes initiation of anionic EO polymerization with a functional alcohol, $\mathrm{F}-\mathrm{OH}$, as suggested by the original work by Rempp et al., who used potassium $p$-isopropenylbenzylate to have a corresponding macromonomer. ${ }^{12}$ Very recently Soula and Guyot $^{7}$ used potassium $p$-vinylbenzylate to sequentially polymerize butylene oxide and EO to a block macromonomer with a sulfonate end group. In our methodology, a functional alcohol was partially alkoxidated with potassium naphthalene $\left(\mathrm{KC}_{10} \mathrm{H}_{8}\right)$ in tetrahydrofuran (THF) to polymerize EO in a living fash- ion to afford $\mathrm{F}-$ and $-\mathrm{OH}$ end-functionalized $\mathrm{PEO}$, $\mathrm{F}-\mathrm{O}\left[\mathrm{CH}_{2} \mathrm{CH}_{2} \mathrm{O}\right]_{n}-\mathrm{H}$, after acidification. In fact, we could readily have $\alpha$ - $p$-vinylphenylalkyl- $\omega$-hydroxyended PEO macromonomers in one step. ${ }^{13}$ On the other hand, the $\omega$-hydroxy-end may be transformed to introduce another functionality, $\mathrm{F}^{\prime}$, to $\mathrm{F}-\mathrm{O}\left[\mathrm{CH}_{2} \mathrm{CH}_{2} \mathrm{O}\right]_{n}-\mathrm{F}^{\prime}$. Thus the strategy can be of potential use in syntheses of various hetero-telechelic PEOs in general. In fact, we have used 2-dimethylaminoethanol (DMAE) Kalkoxide as an initiator of EO polymerization followed by reaction with methacryloyl chloride (MAC) to afford 2-dimethylaminoethoxy-ended PEO -methacrylate macromonomer (Scheme 1a). ${ }^{14}$ Similarly the partial alkoxide of 3-thiophenyl ethanol afforded 3-thiopheneended PEO methacrylate ${ }^{15}$ which can polymerize via either oxidative $\left(\mathrm{FeCl}_{3}\right)$ or radical polymerization.

In this paper, we discuss a general process to prepare $\alpha$ - $p$-vinylbenzyl-ether and $\omega$-tertiary amine-ended PEO macromonomers and their quaternization to have positively charged ends, interesting as the counterparts of those carrying the carboxylate or sulfonate end groups. ${ }^{4-8}$ The charges introduced are expected to add stability to the polymeric microspheres and to prepare extended PEO brushes. Therefore we first tried polymerization of EO with DMAE alkoxide followed by reaction with $p$-vinylbenzyl chloride (VBC). The product obtained, however, was found to include quaternization of the initiator fragment by VBC in addition to the expected $p$-vinylbenzyl ether end-group (Scheme 1b). So instead, we started with $p$-vinylbenzyl alcohol to initiate polymerization of EO, followed by end-group functionalization to introduce tertiary amino groups (Scheme 2).

${ }^{\dagger}$ To whom correspondence should be addressed (Tel: +81-532-44-6814, Fax: +81-532-48-5833, E-mail: itoh@tutms.tut.ac.jp). 
(a)

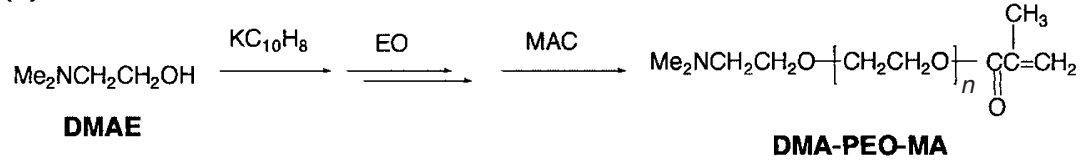

(b)

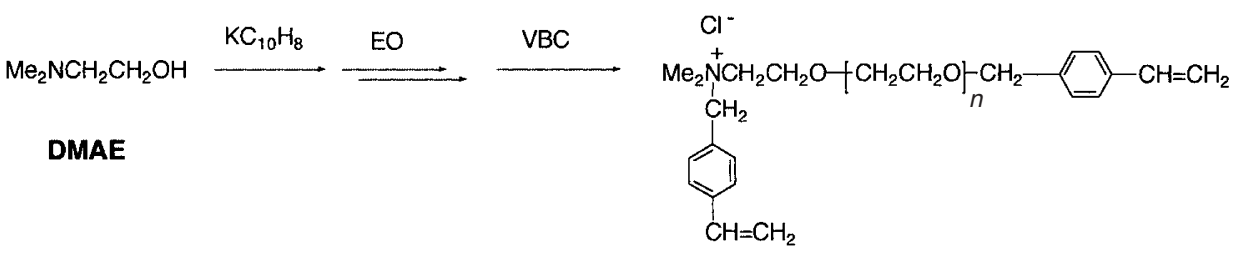

DMVBA-PEO-VB

Scheme 1.

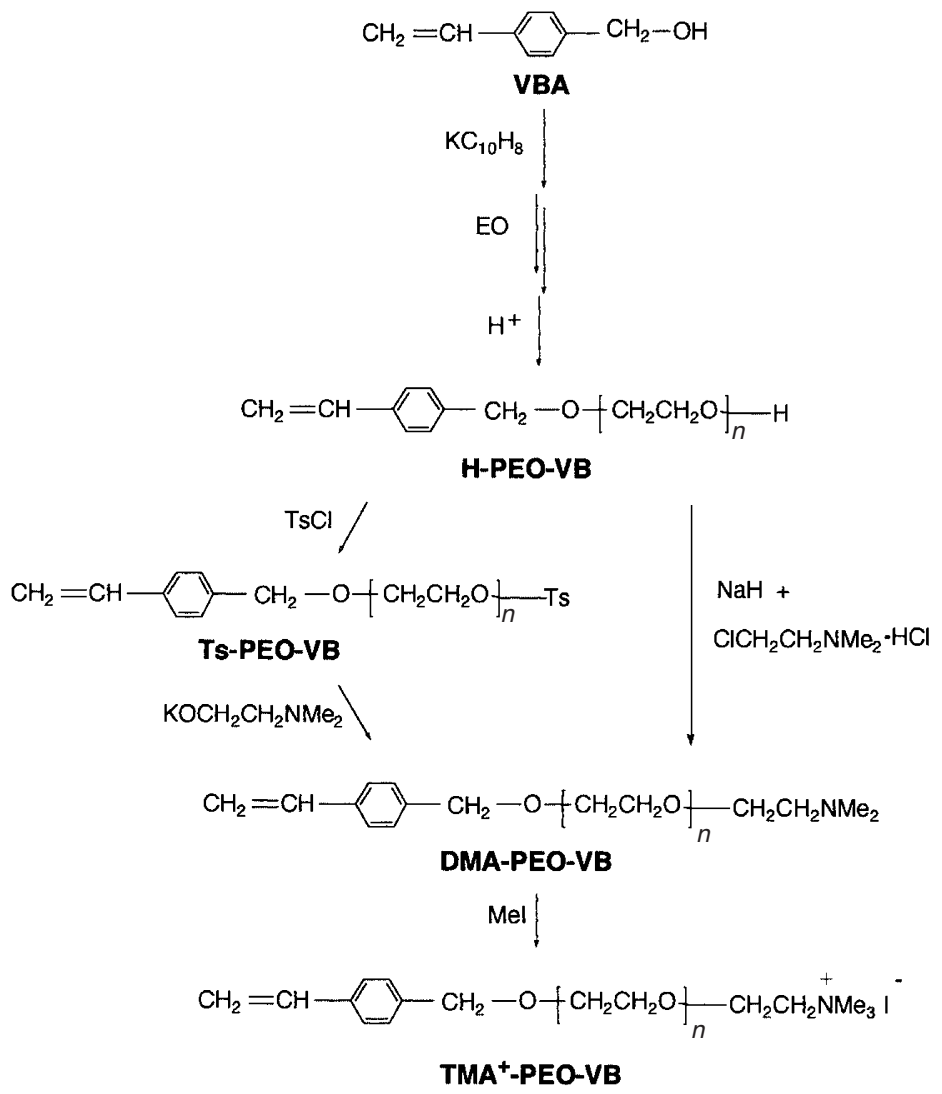

Scheme 2.

\section{EXPERIMENTAL}

\section{Materials}

$p$-Vinylbenzyl alcohol (VBA) was prepared from VBC by reaction with sodium acetate followed by alkaline hydrolysis, according to the procedure described, ${ }^{7}$ and distilled over calcium hydride $\left(\mathrm{CaH}_{2}\right)$ under high-vacuum line, and sealed into calibrated tubes with a breakable seal. Commercial 2-dimethylaminoethyl chloride hydrochloride (DMAC-HCl) (Aldrich) was dried by evacuation under vacuum. 2-
Dimethylaminoethanol (DMAE) (Tokyo Kasei Kogyo) was distilled over $\mathrm{CaH}_{2}$ under vacuum. Commercial sodium hydride $(\mathrm{NaH})$ dispersion $(60 \%$ in oil) (Kishida Chemical), iodomethane (MeI) (Tokyo Kasei Kogyo), and $p$-toluenesulfonyl chloride ( $\mathrm{TsCl}$ ) (Kanto Kagaku) were used as supplied.

Tetrahydrofuran (THF) was distilled from a blue solution with sodium benzophenone. For vacuum line experiment, it was further dried and purified by distillation over $\mathrm{LiAlH}_{4}$ and then over sodium anthracene, and finally from a red solution with disodium salt of $\alpha$-methylstyrene tetramer $\left(\mathrm{Na}_{2} \mathrm{MS}_{4}\right)$ into calibrated 
flasks with a breakable seal. A solution of $\mathrm{Na}_{2} \mathrm{MS}_{4}$ in THF was prepared by reaction of $\alpha$-methylstyrene with sodium mirror at room temperature, filtered, and stocked as dilute solutions in ampoules with a breakable seal. EO was distilled trap-to-trap twice over $\mathrm{KOH}$ pellets, three times over $\mathrm{CaH}_{2}$ powder, and finally over $\mathrm{Na}$ mirror into calibrated tubes with a breakable seal.

Potassium naphthalene $\left(\mathrm{KC}_{10} \mathrm{H}_{8}\right)$ was prepared under high vacuum by reacting naphthalene with excess potassium mirror in THF. Naphthalene was purified by sublimation and dissolved in THF. Potassium mirror was prepared on the wall of a flask after careful trap-totrap distillations over a small oxygen-free flame. The dark green solution obtained was filtered and divided into calibrated tubes with a breakable seal. The concentration was usually $0.2-0.5 \mathrm{~N}$, as determined by titration of an aliquot in water with a potassium hydrogen phthalate solution.

\section{Polymerization of EO}

Polymerization was conducted under high vacuum $\left(5 \times 10^{-5}\right.$ Torr or $\left.3.7 \times 10^{-3} \mathrm{~Pa}\right)$ with all the reagents sealed into appropriate, calibrated ampoules which were also prepared under the vacuum with breakable seal technique. ${ }^{13-15}$ Ampoules including a washing solution $\left(\mathrm{Na}_{2} \mathrm{MS}_{4}\right.$ in THF), VBA as an initiator, THF as a solvent, potassium naphthalene solution $\left(\mathrm{KC}_{10} \mathrm{H}_{8} / \mathrm{THF}\right)$, and $\mathrm{EO}$ were respectively attached into a polymerization flask with a magnetic bar (Figure 1). The apparatus was attached to a vacuum line, evacuated, baked over an oxygen-free flame, and sealed off from the line. The breakable seal of the ampoule of the washing solution (a) was broken with a magnetic bar to rinse all the inner walls. The walls were then completely washed and cleaned by fresh THF, which

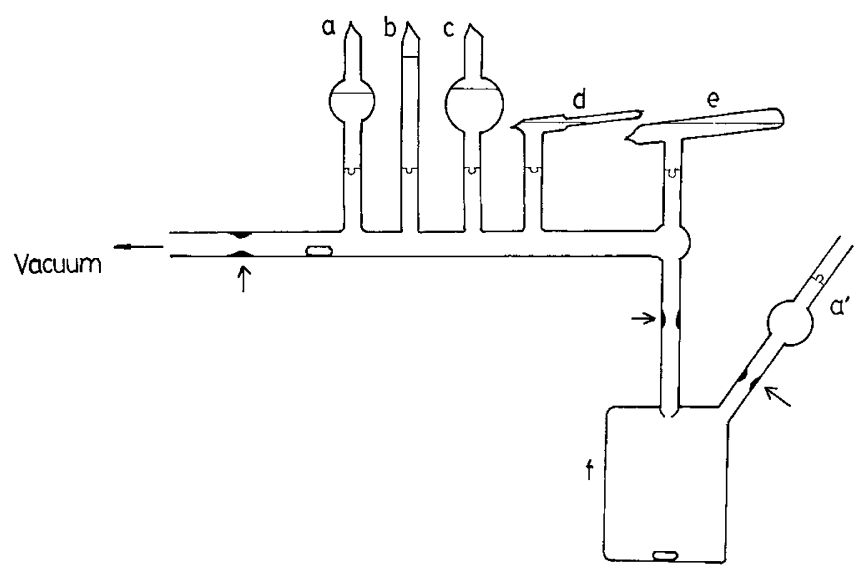

Figure 1. Apparatus for EO polymerization. a, Washing solution $\left(\mathrm{Na}_{2} \mathrm{MS}_{4} / \mathrm{THF}\right) ; \mathrm{a}^{\prime}$, ampoule for recovering a washing solution; $\mathrm{b}$, potassium naphthalene solution $\left(\mathrm{KC}_{10} \mathrm{H}_{8} / \mathrm{THF}\right)$; c, THF; d, initiator alcohol (VBA); e, EO; f, reaction flask. Arrows at the thick wall indicate the points of sealing off. comes on distillation by cooling on the outer walls with cotton tips wetted with isopropanol chilled by dry ice, until the red color of the $\mathrm{Na}_{2} \mathrm{MS}_{4}$ disappeared from the wall. The washing solution was recovered into the flask (a') and sealed off. VBA (d) and solvent (THF) (c) were introduced into the reaction flask. Then the $\mathrm{KC}_{10} \mathrm{H}_{8}$ /THF solution (b) was introduced drop by drop into the flask under vigorous magnetic stirring, so that the dark green color immediately disappeared upon mixing, indicating the reaction of the alcohol to the alkoxide. The degree of alkoxidation was $40-45 \%$ in order to avoid reaction of $\mathrm{KC}_{10} \mathrm{H}_{8}$ with styrenic double bond. ${ }^{13}$ The flask was sealed off and the breakable seal of the chilled ampoule of EO (e) was finally broken to put the monomer into the reaction flask. The flask was then placed in a bath of $40^{\circ} \mathrm{C}$ to start the polymerization. After polymerization for a week, the content was terminated with a small amount of methanol and poured into a large amount of hexane to precipitate out the polymers (H-PEO-VB). The polymers were collected by filtration or by decantation, washed with hexane, reprecipitated three times from benzene into hexane, and finally freeze-dried from benzene.

\section{End-Group Transformation of $\omega$-Hydroxy-PEO} Macromonomers

(1) Tosylation followed by reaction with $\mathrm{KOCH}_{2} \mathrm{CH}_{2} \mathrm{NMe}_{2}$. A solution of H-PEO-VB in THF $\left(10 \mathrm{wt} \mathrm{vol}^{-1} \%\right)$ was stirred with $\mathrm{NaOH}$ (ca. 10 eq) for $30 \mathrm{~min}$ at room temperature. To this mixture, $\mathrm{TsCl}(\mathrm{ca} .5 \mathrm{eq})$ was dropped in over $30 \mathrm{~min}$ and stirred over night. The content was centrifuged and the supernatant was poured into hexane. The precipitates were dissolved in THF and reprecipitated into acetone. The salts were filtered and the filtrate was concentrated and poured into hexane. The polymers, Ts-PEO-VB, were collected, purified three times by reprecipitation, and freeze-dried from benzene under vacuum in an ampoule with a breakable seal. The ampoule was attached to a flask together with ampoules containing a washing solution, THF, and $10 \%$ excess of potassium 2-dimethylaminoethoxide in THF which had been prepared from DMAE and $\mathrm{KC}_{10} \mathrm{H}_{8}$. The reaction was conducted for $24 \mathrm{~h}$ at room temperature under vacuum in a similar procedure as described for EO polymerization. The content was poured into acetone to salt out. The salts were filtered and the filtrate was concentrated and poured into hexane. The polymers, DMA-PEO-VB, were collected, purified similarly, and freeze-dried from benzene. The polymers were obtained in almost quantitative yield.

(2) Williamson reaction with $\mathrm{ClCH}_{2} \mathrm{CH}_{2} \mathrm{NMe}_{2}$. A solution of H-PEO-VB in dry THF $\left(10 \mathrm{wt} \mathrm{vol}^{-1} \%\right)$ was 
Table I. Polymerization of EO to H-PEO-VB ${ }^{\mathrm{a}}$

\begin{tabular}{|c|c|c|c|c|c|c|c|}
\hline \multirow{2}{*}{ Code } & \multirow{2}{*}{$\frac{\mathrm{VBA}}{\mathrm{mmol}}$} & \multirow{2}{*}{$\frac{\mathrm{KC}_{10} \mathrm{H}_{8}}{\mathrm{mmol}}$} & \multirow{2}{*}{$\begin{array}{c}\text { EO } \\
\mathrm{mmol}\end{array}$} & \multicolumn{4}{|c|}{ H-PEO-VB } \\
\hline & & & & $n$ (calc) $^{\mathrm{b}}$ & $n\left({ }^{1} \mathrm{H} \text { NMR }\right)^{\mathrm{c}}$ & $n{\text { (SEC })^{\mathrm{d}}}$ & $M_{\mathrm{w}} / M_{\mathrm{n}}(\mathrm{SEC})^{\mathrm{d}}$ \\
\hline $\mathrm{H}-1$ & 24.4 & 9.8 & 385 & 16 & 21 & 18 & 1.09 \\
\hline $\mathrm{H}-2$ & 14.2 & 5.7 & 578 & 41 & 46 & 40 & 1.06 \\
\hline $\mathrm{H}-3$ & 10.4 & 4.3 & 290 & 28 & 29 & - & - \\
\hline $\mathrm{H}-4$ & 10.4 & 4.7 & 587 & 57 & 57 & - & - \\
\hline $\mathrm{H}-5$ & 5.1 & 2.1 & 552 & 108 & 106 & - & - \\
\hline
\end{tabular}

${ }^{\mathrm{a}} \mathrm{THF}$ : $c a .100 \mathrm{~mL}$, degree of alkoxidation: $\left[\mathrm{KC}_{10} \mathrm{H}_{8}\right] /[\mathrm{VBA}]=0.40-0.45$, temp.: $40^{\circ} \mathrm{C}$, polymerization time: $7 \mathrm{~d}$, conversion: nearly quantitative. ${ }^{\mathrm{b}} n=[\mathrm{EO}] /[\mathrm{VBA}]$ with $100 \%$ conversion assumed. ${ }^{\mathrm{c}} n=\left(I_{\mathrm{EO}} / 4\right) /\left(I_{\mathrm{VBA}} / 2\right)$, where $I_{\mathrm{EO}}=$ peak intensity of the oxyethylene protons at $\delta 3.7$ and $I_{\mathrm{VB}}=$ peak intensity of the benzylic methylene protons at $\delta 4.55$. ${ }^{\mathrm{d}}$ Determined by SEC calibrated with standard poly(ethylene glycol)s and $n=M_{\mathrm{n}} / 44$.

reacted with DMAC- $\mathrm{HCl}(5$ eq) in the presence of $\mathrm{NaH}$ (10 eq), which had been freed from oil by washing with hexane and dried. The mixture was stirred magnetically for $2 \mathrm{~d}$ at $40^{\circ} \mathrm{C}$. The salts were filtered, and the filtrate was concentrated and poured into hexane. The polymers obtained, DMA-PEO-VB, were collected, three times purified by reprecipitation, and freeze-dried from benzene. The polymers were obtained in almost quantitative yield.

(3) Quaternization with MeI. DMA-PEO-VB was dissolved in dry THF $\left(10 \mathrm{wt} \mathrm{vol}^{-1} \%\right)$ and reacted with $\mathrm{MeI}(\mathrm{ca} .10 \mathrm{eq})$ under stirring for one $\mathrm{d}$ at room temperature. The content was centrifuged and the supernatant was concentrated and poured into hexane. Precipitated polymers were collected, three times purified by reprecipitation, and freeze-dried from benzene. The polymers, $\mathrm{TMA}^{+}-\mathrm{PEO}-\mathrm{VB}$, were obtained in almost quantitative yield.

\section{Characterization}

Proton nuclear magnetic resonance $\left({ }^{1} \mathrm{H}\right.$ NMR $)$ spectra were measured on Mercury Varian 300 with deutero-chloroform $\left(\mathrm{CDCl}_{3}\right)$ solutions, with tetramethylsilane as an internal standard. Pulse delay time was $1.5 \mathrm{sec}$ and 16 accumulations were performed. Size exclusion chromatography (SEC) was recorded on JASCO PU980 as a pump, with JASCO RI980 as an RI detector, and Shodex GPC KF-802 and -803 as columns. The eluent was THF with the flow rate of $1 \mathrm{~mL} \mathrm{~min}^{-1}$ at $40^{\circ} \mathrm{C}$. The standard poly(ethylene glycol)s were used for calibration of the molecular weights.

\section{RESULTS AND DISCUSSION}

\section{Polymerization of EO with Partially Alkoxidated VBA}

In macromonomer synthesis, ${ }^{16}$ the initiation method for introducing a polymerizable end-group is of great advantage over the termination method, since the latter usually requires an excess amount of the corresponding terminator to achieve a satisfactory functionality. On the other hand, the requirement of the former is that no reaction occurs between the propagating chain ends and the initiator fragments. As the oxy anions are believed to hardly react with styrenic double bonds, VBA was partially alkoxidated with $\mathrm{KC}_{10} \mathrm{H}_{8}$ to initiate polymerization of EO. Another advantage is the hydroxy group introduced as the other chain end, which may be readily transformed to different functionalities. Here for the purpose of transformation to tertiary amine and quaternary ammonium, we have prepared $\alpha$ - $p$-vinylbenzyl- $\omega$ hydroxy-PEO macromonomers, H-PEO-VB, with various degree of polymerization, $n$, with the result given in Table I. Typical ${ }^{1} \mathrm{H}$ NMR spectra are given in Figures $2 \mathrm{a}$ and $3 \mathrm{a}$.

The values of $n$ calculated kinetically from the EO/VBA molar ratio, those determined by ${ }^{1} \mathrm{H}$ NMR, and those by SEC are in satisfactory agreement with each other. The SEC peaks are sharp in every case with narrow distribution in $n$ or in molecular weight, $M_{\mathrm{w}} / M_{\mathrm{n}} \leq 1.1$, as can be also seen in the SEC data in Table IV for the final products after quaternization. Therefore we can conclude again ${ }^{13}$ that the present polymerization proceeds in clean living mechanism with very fast equilibrium among the potassium alkoxides and the corresponding free alcohols as the active chain ends.

\section{End-Group Transformation of $\omega$-Hydroxy-PEO Macromonomers}

In the first approach, the $\omega$-hydroxy group was tosylated to transform into an electrophilic carbon ${ }^{17}$ and then reacted with potassium 2-dimethylaminoethoxide as a nucleophile. The results, given in Table II with the ${ }^{1} \mathrm{H}$ NMR in Figures $2 b$ and $2 c$, are satisfactory in introducing the tosyl and the tertiary amino end groups.

The second approach is direct Williamson synthesis by reaction of the $\omega$-hydroxy group with 2dimethylaminoethyl chloride in the presence of excess $\mathrm{NaH}$. The results are given in Table III with a typical ${ }^{1} \mathrm{H}$ NMR spectrum in Figure $3 \mathrm{~b}$. The end-group trans- 
( a)<smiles>C=Cc1ccc(COCCOO)cc1</smiles>

b)
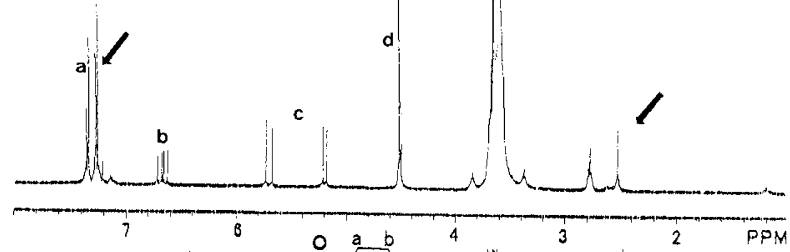

( b)

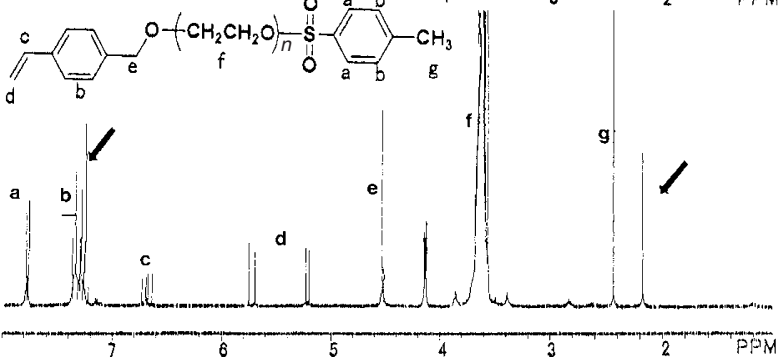

( c)

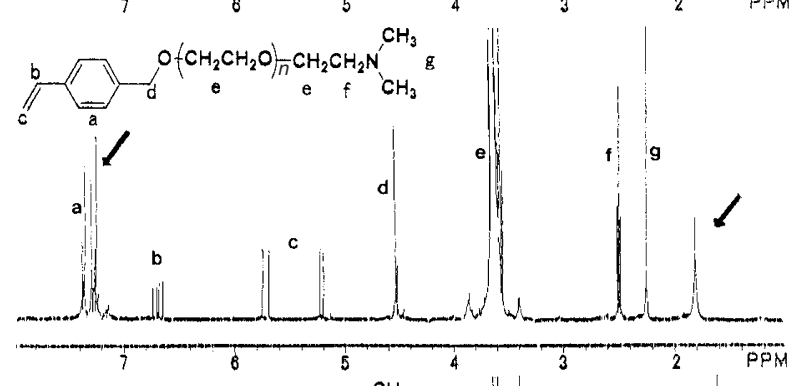

( d)

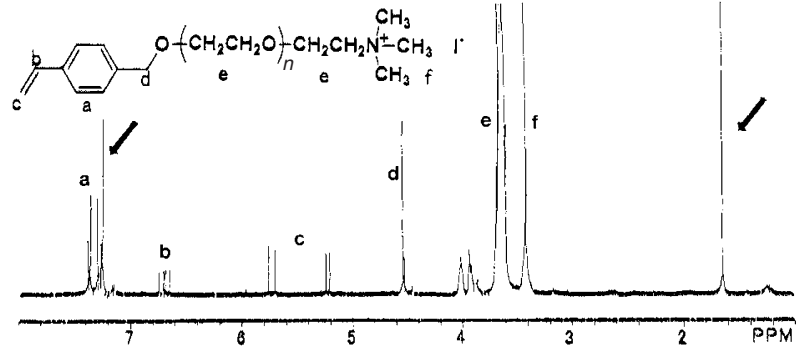

Figure 2. ${ }^{1} \mathrm{H}$ NMR spectra of (a) H-PEO-VB (H-1), (b) TsPEO-VB (Ts-1), (c) DMA-PEO-VB (N-1), and (d) DMA ${ }^{+}$-PEOVB $\left(\mathrm{N}^{+}-1\right)$. Arrows indicate impurities due to $\mathrm{CHCl}_{3}$ and $\mathrm{H}_{2} \mathrm{O}$.

formation was again quantitative.

The final transformation to quaternary ammonium end-group was performed by reaction with iodomethane. The results, summarized in Table IV with typical ${ }^{1} \mathrm{H}$ NMR spectra in Figures $2 \mathrm{~d}$ and $3 \mathrm{c}$, again show satisfactory conversion to the quaternary ammonium end-groups. Some deviation of $n$ by SEC from that by ${ }^{1} \mathrm{H}$ NMR may result from the calibration based on standard poly(ethylene glycol)s without the functional groups such as $p$-vinybenzyl or trimethylammonium. We believe the ${ }^{1} \mathrm{H}$ NMR data are most reliable since both the values of $n$ and $f$ change very little through various transformations.

To summarize, throughout all the transformations performed, the end-group functionalities remain almost perfect and the polymers were isolated almost quantitatively, while the degree of polymerization, $n$, and its distribution are kept essentially the same as
( a)

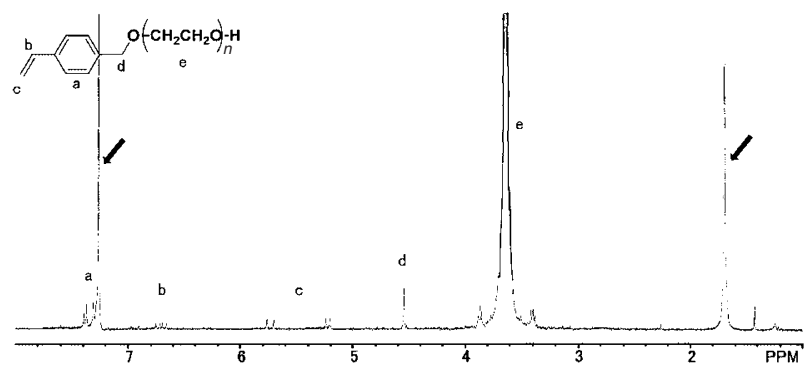

( b)

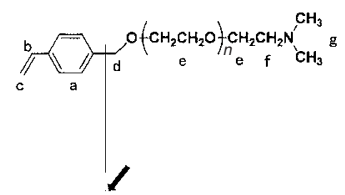

( c)

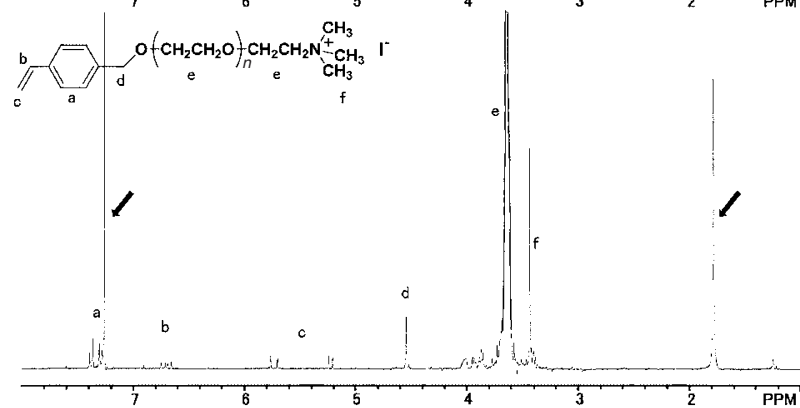

Figure 3. ${ }^{1} \mathrm{H}$ NMR spectra of (a) H-PEO-VB (H-5), (b) DMAPEO-VB (N-5), and (c) $\mathrm{DMA}^{+}-\mathrm{PEO}-\mathrm{VB}\left(\mathrm{N}^{+}-5\right)$. Arrows indicate impurities due to $\mathrm{CHCl}_{3}$ and $\mathrm{H}_{2} \mathrm{O}$.

the original. These results suggest that the present method provides an efficient approach to functional PEO macromonomers as well as hetero-functional or hetero-telechelic PEOs in general.

\section{CONCLUSION}

Initiation of EO polymerization with partially K-alkoxidated VBA afforded well-defined $\alpha$ - $p$ vinylbenzyl- $\omega$-hydroxy PEO macromonomers. $\omega$-Hydroxy group was successfully transformed into tertiary amine either by tosylation followed by reaction with $\mathrm{KOCH}_{2} \mathrm{CH}_{2} \mathrm{NMe}_{2}$ or by Williamson synthesis with $\mathrm{ClCH}_{2} \mathrm{CH}_{2} \mathrm{NMe}_{2}$. Although the latter is preferred for the present objective because of simplicity, both procedures will be useful because various other kinds of nucleophiles and electrophiles may be used for desired end-group transformation. Tertiary amine groups were easily reacted with MeI to afford quaternary ammonium-ended PEO macromonomers. Application of these macromonomers to emulsion and dispersion polymerization of styrene is expected to afford monodisperse polymeric microspheres with surface functionalities such as hydroxyl and 
Table II. Preparation of DMA-PEO-VB via Ts-PEO-VB

(a) Tosylation

\begin{tabular}{|c|c|c|c|c|c|}
\hline \multirow{2}{*}{ Code } & \multirow{2}{*}{$\frac{\mathrm{H}-\mathrm{PEO}-\mathrm{VB}}{\text { code } / \mathrm{mmol}}$} & \multirow{2}{*}{$\frac{\mathrm{NaOH}}{\mathrm{mmol}}$} & \multirow{2}{*}{$\frac{\mathrm{TsCl}}{\mathrm{mmol}}$} & \multicolumn{2}{|c|}{ Ts-PEO-VB } \\
\hline & & & & $n\left(^{1} \mathrm{H} \mathrm{NMR}\right)^{\mathrm{a}}$ & $f\left({ }^{1} \mathrm{H} \text { NMR }\right)^{\mathrm{b}}$ \\
\hline Ts-1 & H-1 / 9.3 & 75 & 26 & 21 & 1.02 \\
\hline Ts-2 & H-2 / 5.7 & 125 & 26 & 45 & 1.01 \\
\hline
\end{tabular}

(b) Reaction with $\mathrm{KOCH}_{2} \mathrm{CH}_{2} \mathrm{NMe}_{2}$

\begin{tabular}{cccccc}
\hline \multirow{2}{*}{ Code } & Ts-PEO-VB & & $\mathrm{KOCH}_{2} \mathrm{CH}_{2} \mathrm{NMe}_{2}$ & & \multicolumn{2}{c}{ DMA-PEO-VB } \\
\cline { 2 - 3 } \cline { 5 - 6 } & code $/ \mathrm{mmol}$ & $\mathrm{mmol}$ & & $n\left({ }^{1} \mathrm{H} \mathrm{NMR}\right)^{\mathrm{a}}$ & $f\left({ }^{1} \mathrm{H} \mathrm{NMR}\right)^{\mathrm{c}}$ \\
\hline $\mathrm{N}-1$ & $\mathrm{Ts}-1 / 4.9$ & 5.5 & 20 & 0.99 \\
$\mathrm{~N}-2$ & $\mathrm{Ts}-2 / 4.2$ & 5.8 & 47 & 0.97 \\
\hline
\end{tabular}

${ }^{\mathrm{a}}$ See the footnote ${ }^{\mathrm{c}}$ in Table I. ${ }^{\mathrm{b}}$ Functionality of Ts end-group: $f=\left(I_{\mathrm{Me}} / 3\right) /\left(I_{\mathrm{VB}} / 2\right)$, where $I_{\mathrm{Me}}=$ peak intensity of the Ts methyl group at $\delta 2.5$ and $I_{\mathrm{VB}}=$ peak intensity of the benzylic methylene protons at $\delta 4.55$. ${ }^{\mathrm{c}}$ Functionality of $\mathrm{Me}_{2} \mathrm{~N}$-end group: $f=\left(I_{\mathrm{Me}} / 6\right) /\left(I_{\mathrm{VB}} / 2\right)$, where $I_{\mathrm{Me}}=$ peak intensity of the $\mathrm{Me}_{2} \mathrm{~N}$ methyl group at $\delta 2.3$ and $I_{\mathrm{VB}}=$ peak intensity of the benzylic methylene protons at $\delta 4.55$.

Table III. Preparation of DMA-PEO-VB via Williamson Synthesis ${ }^{\mathrm{a}}$

\begin{tabular}{|c|c|c|c|c|c|}
\hline \multirow{2}{*}{ Code } & \multirow{2}{*}{$\frac{\text { H-PEO-VB }}{\text { code } / \mathrm{mmol}}$} & \multirow{2}{*}{$\frac{\mathrm{NaH}}{\mathrm{mmol}}$} & \multirow{2}{*}{$\frac{\mathrm{ClCH}_{2} \mathrm{CH}_{2} \mathrm{NMe}_{2} \mathrm{HCl}}{\mathrm{mmol}}$} & \multicolumn{2}{|c|}{ DMA-PEO-VB } \\
\hline & & & & $\overline{n\left({ }^{1} \mathrm{H} \mathrm{NMR}\right)^{\mathrm{a}}}$ & $f\left({ }^{1} \mathrm{H} \text { NMR }\right)^{\mathrm{b}}$ \\
\hline $\mathrm{N}-3$ & H-3 / 10.4 & 106 & 60 & 28 & 1.04 \\
\hline $\mathrm{N}-4$ & H-4 / 10.4 & 105 & 56 & 55 & 1.01 \\
\hline N-5 & H-5 / 5.1 & 106 & 59 & 107 & 0.99 \\
\hline
\end{tabular}

${ }^{\mathrm{a}}$ See the footnote ${ }^{\mathrm{c}}$ in Table I. ${ }^{\mathrm{b}}$ Functionality of $\mathrm{Me}_{2} \mathrm{~N}$-endgroup: $f=\left(I_{\mathrm{Me}} / 6\right) /\left(I_{\mathrm{VB}} / 2\right)$, where $I_{\mathrm{Me}}=$ peak intensity of the $\mathrm{Me}_{2} \mathrm{~N}$-methyl group at $\delta 2.3$ and $I_{\mathrm{VB}}=$ peak intensity of the benzylic methylene protons at $\delta 4.55$.

Table IV. Preparation of TMA ${ }^{+}-\mathrm{PEO}-\mathrm{VB}^{\mathrm{a}}$

\begin{tabular}{|c|c|c|c|c|c|c|}
\hline \multirow{2}{*}{ Code } & \multirow{2}{*}{$\frac{\text { DMA-PEO-VB }}{\text { code } / \mathrm{mmol}}$} & \multirow{2}{*}{$\frac{\mathrm{MeI}}{\mathrm{mmol}}$} & \multicolumn{4}{|c|}{$\mathrm{TMA}^{+}$-PEO-VB } \\
\hline & & & $n\left({ }^{1} \mathrm{H} \mathrm{NMR}\right)^{\mathrm{a}}$ & $f\left({ }^{1} \mathrm{H} \mathrm{NMR}\right)^{\mathrm{b}}$ & $n(\mathrm{SEC})^{\mathrm{c}}$ & $M_{\mathrm{w}} / M_{\mathrm{n}}(\mathrm{SEC})^{\mathrm{c}}$ \\
\hline $\mathrm{N}^{+}-1$ & $\mathrm{~N}-1 / 3.4$ & 17 & 21 & 1.00 & 19 & 1.13 \\
\hline $\mathrm{N}^{+}-2$ & $\mathrm{~N}-2 / 1.7$ & 8 & 45 & 0.96 & 40 & 1.08 \\
\hline $\mathrm{N}^{+}-3$ & N-3 / 10.4 & 76 & 28 & 1.00 & 38 & 1.09 \\
\hline $\mathrm{N}^{+}-4$ & N-4 / 10.4 & 72 & 55 & 1.01 & 63 & 1.01 \\
\hline $\mathrm{N}^{+}-5$ & $\mathrm{~N}-5 / 5.1$ & 71 & 105 & 0.99 & 112 & 1.10 \\
\hline
\end{tabular}

${ }^{\mathrm{a}}$ See the footnote ${ }^{\mathrm{c}}$ in Table I. ${ }^{\mathrm{b}}$ Functionality of $\mathrm{Me}_{3} \mathrm{~N}^{+}$-endgroup: $f=\left(I_{\mathrm{Me}} / 9\right) /\left(I_{\mathrm{VB}} / 2\right)$, where $I_{\mathrm{Me}}=$ peak intensity of the $\mathrm{Me}_{3} \mathrm{~N}^{+}$-methyl group at $\delta 3.5$ and $I_{\mathrm{VB}}=$ peak intensity of the benzylic methylene protons at $\delta 4.55$. ${ }^{c}$ Determined by SEC calibrated with standard poly(ethylene glycol)s and $n=M_{\mathrm{n}} / 44$.

trimethylammonium, as will be published in due course.

\section{REFERENCES}

1. K. Ito, in "Macromolecular Design: Concepts and Practice", M. K. Mishra, Ed., Polymer Frontiers International Inc., New York, N.Y., 1994, p 129.

2. Y. Tanizaki, Yukagaku (Oil Chemistry), 31, 253 (1982).

3. K. Ito, K. Hashimura, S. Itsuno, and E. Yamada, Macromolecules, 24, 3997 (1991).

4. E. Tsuchida, H. Ono, N. Kobayashi, and H. Ishizaka, Macromolecules, 22, 1771 (1989).

5. A. Kishida and M. Akashi, Kobunshi Kako, 44, 242 (1995).

6. T. Iura, S. Kawaguchi, and K. Ito, Polym. Prepr., Jpn., 47, 166 (1998).

7. O. Soula and A. Guyot, Langmuir, 15, 7956 (1999).

8. S. Kawaguchi, K. Deguchi, K. Nagai, M. Sotokawa, and K. Ito, Asia Polymer Symposium, Toyohashi, July 8-12, 2001, Preprints, $\mathrm{p} 125$.
9. a) Y. Nagasaki, R. Ogawa, S. Yamamoto, M. Kato, and K. Kataoka, Macromolecules, 30, 6489 (1997).

b) R. Ogawa, Y. Nagasaki, N. Shibata, H. Ohtsuka, and K. Kataoka, Polym. J., 34, 868 (2002).

10. A. Bucsi, J. Forcada, S. Gibanel, V. Heroguez, M. Fontanille, and Y. Gnanou, Macromolecules, 31, 2087 (1998).

11. M. Niwa and N. Higashi, Macromolecules, 21, 1191 (1988).

12. P. Mason, G. Beinert, E. Franta, and P. Rempp, Polym. Bull., 7, 17 (1982).

13. R. Shen, T. Senyo, C. Akiyama, Y. Atago, and K. Ito, Polymer, 44, 3221 (2003).

14. Y. Yamamoto, W. Nakao, Y. Atago, K. Ito, and Y. Yagci, Eur. Polym. J., 39, 545 (2003).

15. F. Yilmaz, I. Cianga, K. Ito, T. Senyo, and Y. Yagci, Macromol. Rapid Commun., 24, 316 (2003).

16. a) K. Ito, Prog. Polym. Sci., 23, 581 (1998).

b) K. Ito and S. Kawaguchi, Adv. Polym. Sci., 142, 129 (1999).

17. J. M. Harris, E. C. Struck, M. G. Case, M. S. Paley, M. Yalpani, J. M. V. Alstine, and D. E. Brooks, J. Polym. Sci., Polym. Chem. Ed., 22, 341 (1984). 